\title{
Nonlinearities in the price behavior of dairy products
}

www.jestr.org

\author{
E. Zafeiriou* and Th. Koutroumanidis
}

Democritus University of Thrace, Dep. of Agricultural Development, Pantazidou 193 str, 68200, Orestiada, Greece.

\begin{abstract}
Commodity futures risk premiums vary across commodities and over time depending on the level of physical inventories, as predicted by the Theory of Storage. The interaction of the factors related to the inventories and other financial sources result in a complex futures' price behavior especially in the case of dairy products. This behavior has been surveyed and described with non linear testing and modeling respectively within the last decades. The same process has been used to describe the formation of commodity prices. In the present study a number of univariate tests confirm the existence of nonlinearity in the dairy futures price formation, while a Mackey GARCH model is used to describe the returns' behavior. This model selection is based upon the consideration of the mean process as dynamic chaotic. The particular model provides us with a useful tool in making forecasts of a commodity price in the short run but certainly not in the long run.
\end{abstract}

Keywords: GARCH, Nonlinearities, futures prices, dairy products.

\section{Introduction}

A substantial body of research examines volatility patterns in various asset return data, including stock returns and exchange rates, but there exists a much smaller body of research examining the volatility of agricultural commodity futures prices [1]. The value of agricultural commodities is formatted by a numerous of unpredictable factors biological, particularities of breeding and economic.

Dairy producers and manufacturers today face many challenges in operations and in marketing. Dairy prices fluctuate from month to month and make it difficult to ensure meeting break-even costs. Dairy futures and options, however, serve as useful tools for managing the risks inherent to the dairy industry. Options on Dairy futures, in particular, allow producers and manufacturers to limit their price risks, while leaving open the door for profit potential. These markets also attract traders who are willing to accept the risk, in return for potential profits, that dairy professionals seek to transfer.

The dairy markets are unique in that they react very dramatically to small changes in supply and demand. Reductions in supply of 1 percent or less can send prices soaring 50 percent or more within a few months. Increases of 1 percent or less can send prices reeling by the same magnitude. The researchers support that the market of derivatives has beneficial impacts on the underlying market, limiting the volatility given that the derivatives' market acts as a catalyst for the dissemination of information. Particularly, Danthine (1978) concluded that the derivatives' market increases the depth of a market and consequently

\footnotetext{
*E-mail address: ezafir@agro.duth.gr

ISSN: 1791-2377 @ 2011 Kavala Institute of Technology. All rights reserved.
}

reduces its volatility. Stroll and Whaley (1988) in a similar manner claimed that the derivatives enforce the efficiency of a market. According to Schwartz and Laatsch [2], futures increase the depth and the informative power of a market. Figlewski [3] gave an elegant explanation for that: the derivatives' market provides a mechanism for traders of insurance to hedge themselves against undesirable price changes. It distributes risk to a lot of investors and is finally being transferred through hedging spot positions to professional speculators who are capable, and probably willing, of taking it. Consequently, this transfer may reduce the need to embody risk premium in spot market transactions to compensate for the risk variations resulting to a significant improvement of the spot market operation. Furthermore, Lee and Oak [4] claim that well informed speculators mainly buy at low prices, pushing prices up and sell at high prices, thus forcing prices to fall, a fact that stabilizes the market and consequently reduces volatility. The efficiency of a spot market may be improved due to the creation of new channels of information and their rapid evaluation and dissemination. Finally, it is known that derivatives expand investment opportunities, facilitate hedging and improve daily operation leading to a more mature and less uncertain market [5].

The present study uses different univariate tests to detect nonlinearities in the dairy futures prices while a noisy GARCH model is used to capture their movement.

\section{Data}

For the empirical analysis, monthly observations of the CT Dairy Products (Dairy), has been used. The data have been obtained from the Reuters DataLink database of the Thomson Reuters Company. The period studied extends 
from 1.1980 to 12 . 2010. In particular, the monthly returns based on the closing prices have been used. It is evident from the figure 1 , the stationarity of raw data of the dairy futures a result that is confirmed with the application of the $\mathrm{ADF}$ test, and is presented in the following section. The data are characterized by a leptokyrtic distribution a fact that is revealed with the low value of the kyrtosis coefficient (5.199) while the value of the Jarque - Bera coefficient is equal to 205.3364, implying a non normal distribution.

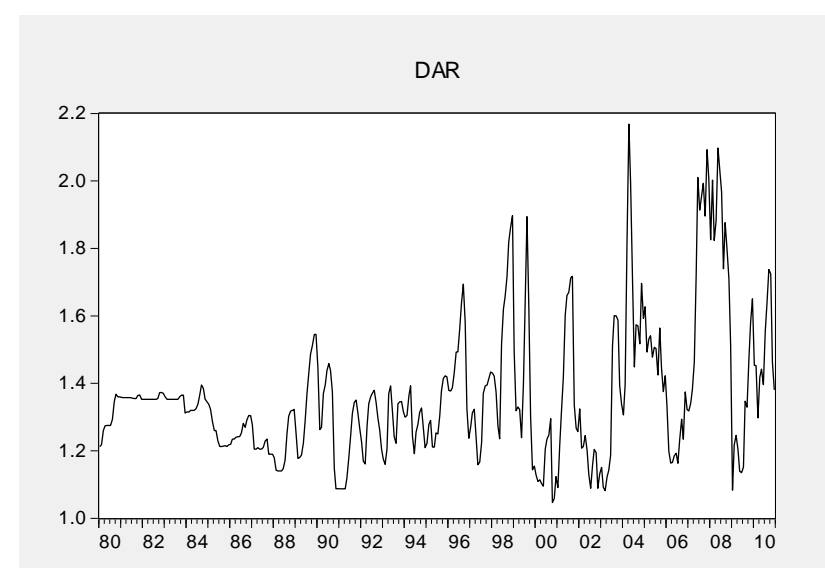

Fig. 1. Evolution of the raw time series

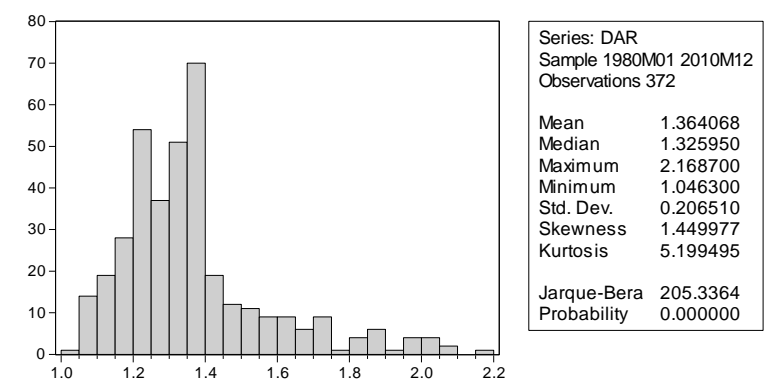

Fig. 2. Graph and statistics of the time series studied (dairy returns)

In order to describe fully our data, an autocorrelation test was also employed. Based on the results we concluded that the time series studied suffers from autocorrelation. This result can be confirmed from figure 3 .

This result necessitates modelling the futures' returns behavior through a model that could eliminate this problem.

\section{Methodology}

The test applied for the survey of nonlinearities in the dairy returns is the BDS test [6], an evolution of correlation dimension test [7]. The test mentioned above is very demanding regarding the size of the sample, since enormous amount of data is needed in case of high dimensional chaos.

BDS test tests the null hypothesis of whiteness (independently and identically distributed observations) against an unspecified alternative through a nonparametric technique. To be more specific the BDS statistic is given by the following equation;
$W(T, m, \varepsilon)=\sqrt{\mathrm{T}} \frac{C(T, m, \varepsilon)-C(T, 1, \varepsilon)}{\hat{\sigma}(\mathrm{T}, m, \varepsilon)}$

where

M: embedding dimension

$\mathrm{C}(\mathrm{T}, \mathrm{m}, \varepsilon)$ : the correlation integral

$\hat{\sigma}(\mathrm{T}, m, \varepsilon):$ an estimate of the asymptotic standard deviation

\begin{tabular}{|c|c|c|c|c|c|c|}
\hline Autocorrelation & $\begin{array}{l}\text { Partial } \\
\text { Correlation }\end{array}$ & & $\mathbf{A C}$ & PAC & Q-Stat & Prob \\
\hline.$|* * * * * *|$ & $|* * * * * *|$ & 1 & 0.893 & 0.893 & 298.89 & 0.000 \\
\hline$|* * * * *|$ & $* *|. \quad|$ & 2 & 0.737 & -0.294 & 503.34 & 0.000 \\
\hline.$|* * * *|$ & .1. 1 & 3 & 0.600 & 0.060 & 639.30 & 0.000 \\
\hline.$|* * * *|$ & .1. 1 & 4 & 0.495 & 0.026 & 731.89 & 0.000 \\
\hline.$|* * *|$ & $.1^{*} \quad \mid$ & 5 & 0.431 & 0.101 & 802.28 & 0.000 \\
\hline.$|* * *|$ & $*|\quad|$ & 6 & 0.374 & -0.077 & 855.51 & 0.000 \\
\hline$.\left.\right|^{* *} \quad \mid$ & $.^{*} \quad \mid$ & 7 & 0.334 & 0.088 & 898.12 & 0.000 \\
\hline$.\left.\right|^{* *} \quad \mid$ & $.1 . \quad \mid$ & 8 & 0.317 & 0.064 & 936.42 & 0.000 \\
\hline$.\left.\right|^{* *} \quad \mid$ & *1. I & 9 & 0.282 & -0.122 & 966.84 & 0.000 \\
\hline$.\left.\right|^{* *} \mid$ & $.1 . \quad \mid$ & 10 & 0.230 & -0.049 & 987.10 & 0.000 \\
\hline$\left.\right|^{*} \quad \mid$ & $.1 . \quad 1$ & 11 & 0.168 & -0.035 & 997.92 & 0.000 \\
\hline$\left.\right|^{*} \quad \mid$ &.$|\quad|$ & 12 & 0.106 & -0.024 & 1002.3 & 0.000 \\
\hline.$|\quad|$ & $* *|. \quad|$ & 13 & 0.022 & -0.232 & 1002.5 & 0.000 \\
\hline$*|\quad|$ & $.1 . \quad 1$ & 14 & -0.066 & -0.018 & 1004.2 & 0.000 \\
\hline$*|. \quad|$ & $.1 . \quad 1$ & 15 & -0.126 & 0.049 & 1010.4 & 0.000 \\
\hline$*|. \quad|$ & $*|. \quad|$ & 16 & -0.165 & -0.070 & 1021.1 & 0.000 \\
\hline$*||$. &. $\mid 1$ & 17 & -0.178 & 0.024 & 1033.5 & 0.000 \\
\hline$*||$. & $.1 . \quad 1$ & 18 & -0.177 & 0.032 & 1045.8 & 0.000 \\
\hline$*|. \quad|$ & .. 1 & 19 & -0.169 & 0.043 & 1057.1 & 0.000 \\
\hline$*|. \quad|$ & $.1^{*} \quad \mid$ & 20 & -0.132 & 0.105 & 1063.9 & 0.000 \\
\hline *|. | & $.^{*} \quad \mid$ & 21 & -0.085 & 0.083 & 1066.8 & 0.000 \\
\hline $.1 . \quad \mid$ & $. l^{*} \quad \mid$ & 22 & -0.034 & 0.116 & 1067.2 & 0.000 \\
\hline $.1 . \quad \mid$ & $.^{*} \quad \mid$ & 23 & 0.022 & 0.086 & 1067.4 & 0.000 \\
\hline $.1 . \quad \mid$ &.$|\quad|$ & 24 & 0.067 & 0.036 & 1069.2 & 0.000 \\
\hline$\left.\right|^{*} \quad \mid$ &.$|\quad|$ & 25 & 0.086 & -0.064 & 1072.2 & 0.000 \\
\hline$\left.\right|^{*} \quad \mid$ & $. l^{*} \quad \mid$ & 26 & 0.100 & 0.087 & 1076.3 & 0.000 \\
\hline.$^{*}$ &. $\mid 1$ & 27 & 0.112 & -0.035 & 1081.3 & 0.000 \\
\hline$\left.\right|^{*} \quad \mid$ &. $\mid 1$ & 28 & 0.127 & -0.022 & 1087.9 & 0.000 \\
\hline$\left.\right|^{*} \quad \mid$ & $. l^{*} \quad \mid$ & 29 & 0.165 & 0.090 & 1098.9 & 0.000 \\
\hline$\left.\right|^{*} \quad \mid$ & $*|\quad|$ & 30 & 0.189 & -0.134 & 1113.4 & 0.000 \\
\hline.$|* * \quad|$ & $. l^{*} \quad \mid$ & 31 & 0.227 & 0.147 & 1134.4 & 0.000 \\
\hline.$|* * \quad|$ & $*|. \quad|$ & 32 & 0.266 & -0.079 & 1163.4 & 0.000 \\
\hline$.\left.\right|^{* *} \mid$ &. $\mid 1$ & 33 & 0.296 & 0.072 & 1199.5 & 0.000 \\
\hline$\left.\right|^{* *} \quad \mid$ & $.1 . \quad 1$ & 34 & 0.323 & 0.035 & 1242.5 & 0.000 \\
\hline$\left.\right|^{* *} \mid$ & $.1 . \quad 1$ & 35 & 0.333 & 0.010 & 1288.4 & 0.000 \\
\hline$.\left.\right|^{* *} \mid$ & .. I & 36 & 0.328 & 0.031 & 1333.0 & 0.000 \\
\hline
\end{tabular}

Figure 3: The correlogram of the time series studied

The statistic BDS under the null hypothesis is asymptotically normal [8]. This test was applied on our data, while the time series studied was investigated with the ADF 
test in order to examine the stationarity of the series and was found stationary in levels.

The next step involves the survey of autocorrelations in the time series studied. This survey is based on the Q test for 36 lags of the time series studied. The next univariate tests employed for the survey of nonlinearities are the MC Leod Li [9] and Engle [10] tests.

The first test may be conducted with the application of the Box - Ljung Q statistic of the squared residuals. An ARMA process is preceded aiming at the filtering of our data. The initial (raw) data may be examined with the use of the $\mathrm{k}$ autocorrelation coefficients for $\left\{\mathrm{x}_{\mathrm{t}}\right\}$ and $\left\{x_{t}\right\}$ and $\left\{x_{t}^{2}\right\}$. The $\mathrm{Q}$ statistic is used aiming at the examination of the existence of serial correlation.

According to this method a time series follows an i.i.d. process (under the null hypothesis) if for a fixed $\mathrm{L}$ the following equation;

$$
\mathrm{T}^{\frac{1}{2}} \rho^{2}(k)=\left[\rho^{2}(1), \ldots, \rho^{2}(L)\right]
$$

is asymptotically a multivariate unit normal.

As a consequence, for a high value of $\mathrm{L}$, the Box - Ljung statistic $Q \sim x^{2}(L)$. Q is given by the following equation;

$$
Q=T(T+2) \sum_{j=1}^{L} \frac{\rho^{2\{[\kappa]\}^{2}}}{\mathrm{~T}-j}
$$

The null hypothesis is that of a linear generating mechanism for the data. The other test Engle, examines the non - linearity through a Lagrange multiplier test in the second moments. This test preconditions the regression of the squared residuals;

$$
\hat{\varepsilon}_{t}^{2}=a_{0}+\sum_{j=1}^{\rho} \alpha_{j} \varepsilon_{t-j}^{2}+u_{t}
$$

The non - existence of ARCH - type effects means the coefficients are non - significant and thus the regression will have a limited explanatory power while the coefficient of determination is very low. According to the null hypothesis given that the sample size is $\mathrm{T}$, there are no $\mathrm{ARCH}$ - type effects and the statistic used for this test is the $\mathrm{TxR}^{2} \sim x_{p}^{2}$. If $\mathrm{TxR}^{2}$ is large enough then we reject the null hypothesis under which there is no ARCH - type errors.

The final step employed in the me methodology applied involves the estimation of Mackey GARCH $(p, q)$ model. In order to model the observed dynamics in financial markets we use an equation that includes two parts. The first part is deterministic (intrinsic deterministic dynamics) and the other one is the stochastic part (the random noise). The model might have the following form;

$$
X_{t}=f\left(X_{t-1}, \ldots\right)+\varepsilon_{t}
$$

where;

$$
\begin{aligned}
& X_{t}: \text { observable non - linear function } \\
& f: \text { a deterministic non-linear function } \\
& \varepsilon_{t} \sim \text { iid }
\end{aligned}
$$

In order to detect the complexity of the financial time series we are going to use a version of the Mackey - Glass equation [11]. This model is a noisy Mackey - Glass equation whose errors follow a $\operatorname{GARCH}(\mathrm{p}, \mathrm{q})$ process. That is why it is called a MG - GARCH (p, q) model. The particular model provides us with an econometric tool to study volatility - clustering phenomena as a result of an endogenous process. The existence of volatility clustering stems from the interactions between fundamentalists and noisy traders [12]. The behavior of the noisy traders cannot be explained and thus it is given exogenously. This is the stochastic part of the Mackey - Glass equation. The deterministic part of the MG - GARCH (p, q) model represent the determinant stock prices given that the market is dominated by fundamentalists. As fundamentalists, are considered the traders who have rational expectations (are based on the information from the macroeconomic environment), regarding the future price and dividends of an asset [13]. This fact is not valid in reality though and that is why this equation cannot represent all the traders. The model is provided by the following equations;

$$
\begin{aligned}
& R_{t}=\alpha \frac{R_{t-\tau}}{1+R_{t-\tau}^{c}}-\delta R_{t-1}+b R_{t-j}\left(1-R_{t-j}\right)+\varepsilon_{t} \\
& h_{t}=\alpha_{0}+\alpha_{1} \varepsilon_{t-1}^{2}+\beta_{1} h_{t-1}
\end{aligned}
$$

where

$$
\begin{aligned}
& \mathrm{t}, \mathrm{j}: \text { denote the delays } \\
& \mathrm{c}: \text { constant } \\
& \mathrm{R}_{\mathrm{t}}: \text { the returns } \\
& \mathrm{h}_{\mathrm{t}}: \text { the GARCH variance }
\end{aligned}
$$

The part $a \frac{R_{t-\tau}}{1+R_{t-\tau}^{c}}-\delta R_{t-1}$ filters the dynamics that positive feedback trading causes, consisting the discretized version of the model under preview, whereas the part $b R_{t-j}\left(1-R_{t-j}\right)$ models structures that may be attributed to negative feedback in the market. The positive feedback describes the investors that buy when the price rises and sell when the price falls. The negative feedback describes the opposite investors' behavior.

The main advantage of this model is that two nonlinear trading strategies may capture more complicated dynamics. To be more specific this model consists a more realistic approach given that the assumption of the existence of more than one type of investor as the driving force of endogenous perturbations is more realistic.

\section{Results - Discussion}

Initially, within the effort to survey the time series studied we employed the ADF stationarity test on the closing prices as well as on the time series of returns generated by the closing prices. For the first time series we confirm that the time series is $\mathrm{I}(1)$, while for the time series of returns stationarity is confirmed. The aforementioned results are presented in the following table 1;

Table 1. Results of ADF Test 


\begin{tabular}{ll}
\hline Variable & ADF statistic \\
\hline $\mathrm{cp}$ & -1.2355 \\
$\Delta \mathrm{cp}$ & -28.03215 \\
$\mathrm{r}$ & -38.1117 \\
$\Delta \mathrm{r}$ & -
\end{tabular}

Notes: The critical values for this test since only constant and no trend is included are $-3.43,-2.86$ and -2.567 for $1 \%, 5 \%$ and $10 \%$ respectively.

The application of the BDS independence test is the second stage within our methodology and has given the results presented in the following table 2 ;

$\underline{\text { Table 2. BDS Statistics at Dimensions (M) } 2-6}$

\begin{tabular}{ll}
\hline$\underline{\mathrm{m}}$ & $\underline{\varepsilon}$ \\
\hline 2 & 0.009083 \\
3 & 0.015522 \\
4 & 0.019424 \\
5 & 0.023342 \\
6 & 0.025219 \\
\hline
\end{tabular}

Based on the aforementioned results the null hypothesis of independent and identically distributed observations is rejected. This result can confirm neither nonlinearity nor chaotic behavior [13]. This test provides indirect evidence regarding the nonlinear dependence either chaotic or stochastic a necessary but not a sufficient condition for chaos [14].

Employing Mc Leod Li and Engle test has given us the results presented in the following table 3 ;

Table 3. Significance Level for Mcleod Li and Engle Test

\begin{tabular}{lll}
\hline Series & $\begin{array}{l}\text { McLeod }-\mathrm{Li} \\
(\mathrm{L}=22)\end{array}$ & $\begin{array}{l}\text { Engle } \\
(\mathrm{p}=4)\end{array}$ \\
\hline$\Delta \mathrm{c}$ & 0.000 & 0.000 \\
\hline
\end{tabular}

The null hypothesis in Mc Leod Li test suggests that there is a linear generating mechanism while in Engle test the null hypothesis suggests that there is no ARCH - type effects.

Rejection of null hypotheses in both tests confirms the existence of nonlinearities and ARCH heteroscedasticity for the time series studied respectively.

Based on the aforementioned results we may model the returns behaviour with a non linear GARCH model. The best fit GARCH model is the GARCH $(1,1)$ model while the mean equation is non linear $(c=2, \tau=1)$. The values of the aforementioned features are determined by the Akaike criterion as well as the order of the GARCH model. The results of the estimated model are presented in the following table 4;

Table 4. CMG - Garch $(1,1)$ estimation results

\begin{tabular}{lll}
\hline Coefficient & Estimate & $\mathrm{z}$ - statistic \\
\hline$\alpha$ & 0.661167 & 8.864859 \\
$\delta$ & -0.703272 & 22.03221 \\
\hline
\end{tabular}

\begin{tabular}{lll}
\hline $\mathrm{b}$ & 0.2235 & 7.2842 \\
$\alpha_{0}$ & 3.42 & 1.8855 \\
$\alpha_{1}$ & 0.062832 & 5.276562 \\
$\beta_{1}$ & 0.953397 & 4.44325 \\
\hline
\end{tabular}

All the estimated coefficients are statistically significant confirming the nonlinearity of the mean equation in the Mackey GARCH $(1,1)$ model. Furthermore, noisy chaotic structures are responsible for nonlinearity in the mean of the time series under preview.

Based on the aforementioned model we conducted a forecast, while the two coefficients RMSE and MAPE have given us the following results;

RMSE $=0.000822$

MAPE $=79.32$

Based on the aforementioned results we may conclude that the particular model provides us with a satisfactory forecasting tool at least in the short term.

The residuals of the estimated equation do not have a problem of low kyrtosis coefficient or a problem of normality nor a problem of autocorrelation, as confirmed by the use of different tests. Regarding the problem of heteroscedasticity, or homoscedasticity, of the residuals of the estimated model it is necessary to mention that the attractor of this equation has heteroscedastic errors given that the particular equation follows a $\operatorname{GARCH}(1,1)$ process.

\section{Conclusions}

Chaotic behaviour of macroeconomic data has been a subject of extensive study in the past but the evidence for its existence is extremely weak [15]. On the other hand, the studies of commodity prices have generally found evidence consistent with low dimension chaos. The chaos on the other hand is confirmed in many cases of the commodity prices. One could argue that seasonality or short data spans may account for this diversity in the results found. Nonlinearities were detected with a number of univariate tests. For the tests we employed daily data of dairy futures' prices for a time period of seven years, derived by Reuters.

Independence of the observations has been rejected according to the results of the BDS test. This result though, provides no evidence for non - linearities in the price behavior. Thus, other tests were implemented in order to confirm the existence of non linearities such as Engle and McLeod and $\mathrm{Li}$ tests. The results of those tests confirmed that the behavior of the time series is nonlinear, a result that is consistent with other studies that examined the nonlinearity of other financial time series [13,16]. In addition [15] in another study where the futures prices of agricultural products were surveyed, nonlinearities were confirmed, a result for which seasonality and contract maturity effects may account. As far as the estimation of the Mackey GARCH model and the satisfactory results of the forecast criteria provide the policy makers or the managers of an agricultural firm with a useful tool in order to make adequate short term forecast for the futures' prices. Another important finding of this study is the sign of the non linear parts in the mean equation of the GARCH model. The results in our case oppose that of other studies that involves futures prices of other products and can be explained as 
follows; the positive shocks in agricultural markets are bad news, leading the investors, consumers and speculators to take larger position and consequently to increase even more the returns leading to a greater volatility [5].
The present survey may be further extended by modeling the returns' behavior with a seasonal Mackey GARCH model as suggested by recent studies [17].

\section{References}

1. J. Elder, Jin H. J., Long Memory in Commodity Futures Volatility: A Wavelet (2007)

2. T.V. Schwartz, F. Laatsch, Price discovery and risk transfer in stock index cash and futures markets, Journal of Futures Markets, 11669 (1991).

3. S. Finglewski, Futures trading and volatility in the GNMA market, Journal of Finance, 25383 (1981).

4. S.B. Lee, K.Y. Ohk, Stock index futures listing and structural change in time-varying volatility, The Journal of Futures Markets, 12493 (1992).

5. N. Sariannidis, The Impact of Stock, Energy and Foreign Exchange Markets on the Sugar Market. International Journal of Economic Sciences and Applied Research 1109 (2010).

6. W. Brock, D. Hsieh, B. Le Baron, Nonlinear dynamics, chaos, and instability: statistical theory and economic evidence. MIT Press, (1993).

7. Kyrtsou C., Serletis, A., 2006. Univariate tests for nonlinear structures. Journal of Macroeconomics 28, $154-168$.

8. W.A. Brock, W. D. Dechert, B. Lebaron, J.A. Scheinkman, A test for independence based on the correlation dimension. Econometric Reviews 15197 (1996).

9. A.I. McLeod, W.K. Li, Diagnostic checking ARMA time series models using squared residuals autocorrelations. Journal of Time Series Analysis 4269 (1983).
10. R.F. Engle, Autoregressive conditional heteroskedasticity with estimates of the variance of United Kingdom inflation. Econometrica 50987 (1982).

11. M. Mackey, L. Glass, Oscillation and chaos in physiological control systems. Science 50287 (1977).

12. C. Kyrtsou, Evidence for neglected linearity in noisy chaotic models. Working paper, LAMETA, University of Montpellier I, (2003).

13. C. Kyrtsou, Heterogeneous non-linear agents strategies and routes to chaotic dynamics. Working Paper, LAMETA, University of Montpellier I, (2006).

14. W. A. Barnett, R. A. Gallant, M. J. Hinich, J. A. Jungeilges, D.T. Kaplan, M. J. Jensen, A single blind controlled competition among tests for nonlinearity and chaos. Journal of Econometrics, 82, 157 (1997).

15. A. Chatrath, A. Bahram, D. Kanwalroop, Are commodity prices chaotic? Agricultural Economics 27123 (2002).

16. C. Kyrtsou, M. Terraza, Misleading linear properties for a noisy chaotic model", Working Paper. LAMETA, Department of Economics, University of Montpellier I (2001).

17. C. Kyrtsou, M. Terazza, Seasonal Mackey-Glass-GARCH process and short-term dynamics. Empirical Economics, 38325 (2010). 